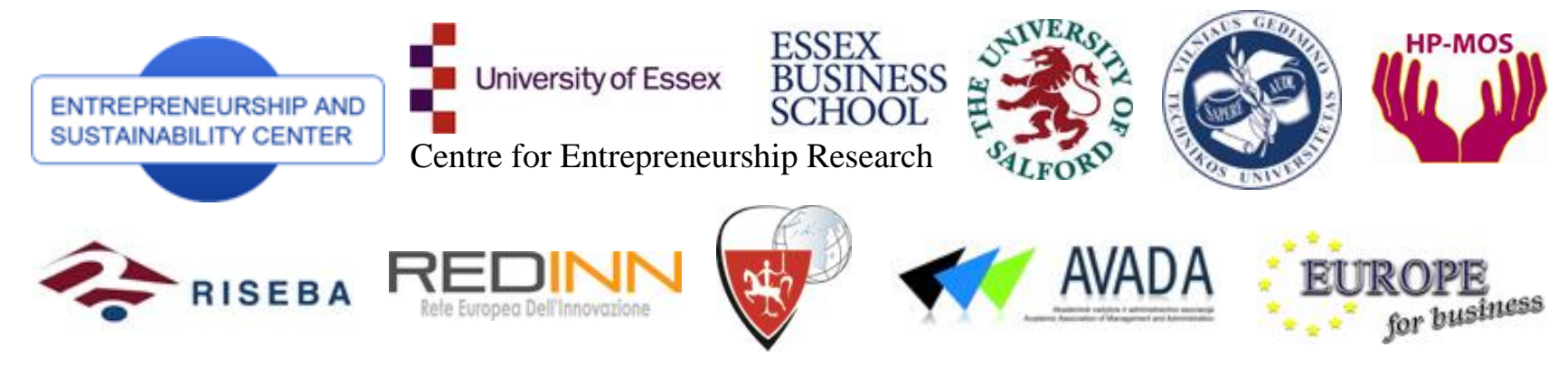

ENTREPRENEURSHIP AND SUSTAINABILITY ISSUES

ISSN 2345-0282 (online) http://jssidoi.org/jesi/aims-and-scope-of-research/

2013 Volume 1(2): 81-91

http://dx.doi.org/10.9770/jesi.2013.1.2(2)

\title{
IMPACTS OF SUSTAINABLE STRUCTURAL GROWTH ON THE ECONOMIC PERFORMANCE OF LISTED COMPANIES
}

\author{
Mindaugas Laužikas ${ }^{1}$, Antanas Krasauskas² \\ ${ }^{1,2}$ International Business School at Vilnius University \\ Sauletekio av. 22. Vilnius LT-10225, Lithuania \\ E-mails:1 mindaugas.lauzikas@gmail.com; 2akkrasauskas@gmail.com
}

Received 15 August 2013; 3 accepted 30 September 2013

\begin{abstract}
The purpose of the present publication is to measure the impacts of structural growth on the economic sustainability of listed companies. Scientific literature overview, secondary data analysis and semi-structured qualitative interviews were combined in order to examine the effects of structural growth. The research question is how structural changes of listed companies affect their sustainable growth. Scrutinizing various cases makes it possible to tackle the patterns of sustainable structural growth, based on a type of structural change. Many researchers (such as Huang and Kleiner 2004; Deal and Kennedy 1982 or Pritchett and Gilbreath 1996 and etc.) and business analysts (such as KPMG consulting company 1999) have not found a common answer what are the key success factors of structural growth. It is related to strategic targets, due diligence activities, expenses (the transactional decisionmaking phase) or integration planning, the organizational culture, assimilation or dissimilation (the integration phase). Franks and Harris (1989) emphasize the increase in shareholders' value as the main motive for structural changes. Boucher (1980) argues that the two most common reasons of structural changes are either attempts of taking opportunities present in the market, or increasing the growth. The present research, which combines the analysis of secondary data and semi-structured qualitative interviews, aims to verify various researchers' statements. Based on the scientific literature analysis, two conceptual models are designed and verified. This should serve as the background for the further examination of the role of structural changes on a sustainable companies' growth and new publications in the same series.
\end{abstract}

Keywords: Mergers, takeovers, business formation, business management, performance evaluation, performance indicators, financial markets, financial management, sustainability.

Reference to this paper should be made as follows: Laužikas, M.; Krasauskas, A. 2013. Impacts of sustainable structural growth on the economic performance of listed companies, Entrepreneurship and Sustainability Issues 1(2): 81-91. http://dx.doi.org/10.9770/jesi.2013.1.2(2)

JEL classification: G32, G34, L21, M13.

\section{Introduction}

Companies of different sectors, size, lifetime, and business development stages face their specific needs to grow revenues and profits while strengthening their competitive advantages: some of them are involved in structural changes; others keep focusing on an organic growth. In both scenarios the principle objective is their economic performance. The Penrose's (1959) observation that growth is one of the key indicators and goals of any business elucidates an important pattern that rapidly growing businesses are more attractive among shareholders (Tosi et al. 2000). Langford and Male (2001) identify three types of growth: organic 
growth, growth through structural changes, such as mergers and acquisitions, and combination of the two methods. According to Irvin et al. (2003, the organic growth is assumed to be the least risky and costly growth, with fewer problems in internal communication, adaptation and organization of processes. However, it can also be characterised as causing the smallest amount of sudden changes in activities of a company, while being more predictable. Irvin et al. (2003) also relate organic growth to not using external resources and expanding as much as the market allows: the market is growing and companies are increasing their share in the market.

As the limitation it should be stated that the organic growth in mature markets rarely exceeds $3-5 \%$ on the year-to-year basis, excluding the expansion to new niches and new product lines. Samuelson and Nordhaus (2001) emphasize that organic growth might lead to overinvestment, as past some point the returns on investment start to become lower and lower; then the external growth strategies should be examined. This can be related to the limited client base or too high production costs of additional goods (Ethier 1982).

Meer (2005) believes that organic growth is more suitable in emerging markets because it helps to avoid risky investments and reach the stability within a company, which is in general related to sustainable improvements rather than a temporary growth. Lockett et al. (2011) go one step forward and underline the importance of planning and business modelling in order to achieve a sustainable organic growth.

The structural growth is often called inorganic growth or growth through structural changes. Based on Varaiya et al. (1987), this kind of development is to compensate the lack of organic growth. According to Reddy et al. (2013), companies often strengthen their performance via merging or acquiring competitors in mature markets, while within emerging markets it can serve as an accelerator of growth. Danescu (2011) draws attention to the synergy effect, merging 'know-how', increasing owned assets and revenues in the short run, which can lead to better borrowing possibilities and decreasing costs of loaning. Dalton, D.R. and Dalton,C.M. (2006) suppose that the principle challenges of structural growth of companies are related to the incorporation of newly acquired assets and human resources into the company. The organizational communication, processes, structural planning, asset and wealth allocation, organizational culture, application of expertise and many other issues follow the merger or acquisition. In addition to the analysis of mergers and acquisitions there should be an adequate attention paid to spin-outs and demergers that often are responsible for inorganic growth, although they mean splitting a company into more entities. It is obvious that sometimes splitting contributes to a better performance of a company or new companies, and can deliver shareholders a higher value-added.

Passing through different stages of development a company normally experiences both organic and inorganic growth and sometimes needs to combine both at the same time; it provides the diversification and balance and implies the sustainability of a business. It also requires from managers the expertise of managing two types of development. As it is stated by Delaney and Wamuziri (2004), the joint ventures could be a good example of such combination, where a newly formed company is owned by at least two companies.

Another important aspect the concept of sustainability refers to is the long-term orientation and consistency in business processes: the growth rates should be long-lasting, while improving one economic indicator companies should not worsen another one. Therefore, the present article is to measure the impacts of structural growth on the economic sustainability of companies, and the combination of such research methods as the scientific literature analysis and semi-structured qualitative interviews helps to answer to the research question, and to illustrate the role of structural changes via various cases and scientific insights.

\section{Peculiarities of mergers and acquisitions}

To understand better the impacts of structural changes it is reasonable to distinguish the differences between mergers and acquisitions. Based on the Lithuanian Civil Code (2000), the main difference between mergers and acquisitions is the form in which the ownership and legal status of organizations is organized: during the merger an entirely new company is formed, ending existence of companies that are merged, whereas during the acquisition process one company is merged to other during the integration process, and, thus, the acquiring company keeps its' legal status. While acquiring the ownership of another company, a company also acquires all the assets and liabilities of that company. When the target company is well-known and of significant importance, some characteristics or name of acquiring company might be changed. Weston et al. (2004) distinguishes three main types of mergers, according to the relationship of companies that are 
merging: horizontal mergers (mergers between companies competing in the same industry), vertical mergers (mergers where one company is a supplier for another), and conglomerate mergers (mergers between companies that do not have any direct relationship between each other, do not have complementary markets or production processes and have no competing products). Within the case of horizontal mergers the government should eliminate possibilities of the breach of concurrence law and the appearance of monopolies (Poindexter 1970). Kumar (2009) pays a special attention to industry roll-ups that include small, yet mature companies, without dominant leader. Such clusters intend to achieve the economy of scale in terms of such aspects as purchasing, IT, distribution via minimizing the part of administrative costs in the total expenditure. Stacey (1966) tackles the specificity of vertical mergers, where firms are in general in different stages of production operations: thus, the decrease in costs related to pricing, contracting, payment collection, advertising, and communicating are the basic focus of such changes. Baker et al. (1981) scrutinize patterns of conglomerate mergers, where product extension mergers (can also be called concentric mergers), geographic merger extensions and mergers between companies from completely unrelated business activities are possible. In many cases the value-added is generated via discounted cash flows.

In parallel to the classification of mergers there should be the typology of acquisitions explained. Jennings and Mazzeo (1986) examine such acquisitions as hostile takeovers, when the acquisition is executed in spite of disagreement of governing bodies (via direct proposal to shareholders or replacing managers of a company). Kosedag et al. (2009) tackle the reverse takeover cases, when a company performs the acquisition of a public company and enters the public market through such transaction in order to avoid a lengthy process of going public through Initial Public Offerings (IPOs). It can also help mitigate risks related to the volatility (mood swings and cycles) in the public markets. According to Hall and Norburn (1987), the majority of acquiring firms tend to suffer significant losses in returns or enjoy positive minor returns temporarily. Firth (1980) adds that returns are starting shrinking rapidly right after completing acquisition processes, whereas studies by Michel et al. (1983) and Dodds and Quek (1985) indicate the period of 55 months during which a negative effect of acquisition completely cancels out previous gains and returns a company to the point where they have gained nothing from acquisitions. There is a consensus among such scholars as Wansley et al. (1983) that an acquiring company rarely experiences benefits from acquisitions, while the shareholders of an acquired company experience substantial gains.

After conducting the research involving 168 cases of acquisitions of listed companies Sirower (1997) suggests that in many cases where acquisitions produced synergies and improved the overall organizational performance, they still failed to repay the premium that the acquiring company had to pay. Another study by KMPG International (1999) found that around 83 per cent of mergers and acquisitions failed, being translated to the decrease in the productivity, loss of shareholders' value and worse performance by the staff mainly due to bad planning and execution. On the other hand, all the Big4 companies of auditing and accounting sector experienced at least two relatively successful mergers in their history by 2013, because of having a sufficient know-how and management skills. Huang and Kleiner (2004) believe that only 23 per cent of acquisitions fixed their cost of capital, whereas around 75 per cent of executives of acquired companies left within three years of acquisition. Even though there are some authors who argue that $\mathrm{M}$ and A's have positive or at least neutral effect (Gould 1998) not taking into account the price of acquisitions. Maquieira et al. (1998) after examining 260 mergers in the USA identify significant differences between horizontal and conglomerate mergers. Horizontal mergers profited from significant synergistic benefits and experienced substantial gains, whereas conglomerate mergers experienced either very low gains or none at all. In some cases, where conglomerate mergers served as defensive diversifications, they have generated improvements in financial results of companies (Cornett and Tehranian 1992). In addition, some well-known American researchers have found significant improvements in post-takeover results of companies and industry-adjusted cash flows within these companies (Healy et al. 1992).

Apart from a few researchers with findings in favour of mergers and acquisitions, the majority of studies came up with results revealing the negative or neutral impact. Berger and Humphrey (1992) have found no significant improvements in post-merger results of conglomerate mergers. Finally, Peters and Austen (1985) state, that only motives and targets help to justly evaluate the success of any merger or acquisition. Some researchers argue that mergers and acquisitions nowadays act as a tool to gain advantage in corporate arena where managers compete for control and possibility to manage more resources (Jensen and Ruback 1983). Within the study performed for the Federal Trade Commission by Boucher (1980), 31 key motives for acquisitions were identified, where the top 12 motives are presented in Table 1. Levinson (1970) found quite 
strong evidence that behind rational reasons there were psychological reasons often causing condescending and manipulative attitudes towards other parties of a transaction. Graebner et al. (2010) distinguish three main buyer motives and two main seller motives in such transactions. The main buyer motives are the addition of strategically valuable resources, enhancing market power and achieving strategic renewal.

Table 1. Most popular motives of acquisitions

\begin{tabular}{|l|c|c|}
\hline \multicolumn{2}{|c|}{ Motives for acquisition } & \multicolumn{2}{c|}{ Sotive } & Score & Rank \\
\hline \multicolumn{1}{|c|}{ Make advantage of awareness that a company is undervalued } & 18,2 & 1 \\
\hline Achieve growth more rapidly than by internal effort & 16,9 & 2 \\
\hline Satisfy market demand for additional product services & 14,5 & 3 \\
\hline Avoid risks of internal start-ups or expansion & 14,3 & 4 \\
\hline Increase earnings per share & 14,2 & 5 \\
\hline Reduce dependence on a single product/service & 13,5 & 6 \\
\hline Acquire market share or position & 11,6 & 7 \\
\hline Offset seasonal or cyclical fluctuations in the present business & 10,5 & 8 \\
\hline Enhance the power and prestige of the owner, CEO or management & 10,2 & 9 \\
\hline Increase utilisation of present resources - e.g. physical plant, individual skills, etc. & 9,3 & 10 \\
\hline Acquire outstanding management or technical personnel & 8,9 & 11 \\
\hline Open new markets for present products/services & 8,5 & 12 \\
\hline
\end{tabular}

Source: Boucher (1980)

The main seller drivers are adding strategically valuable resources and relieving personal pressures off leaders within acquired companies. The motives are accompanied by conditions and factors to make a structural growth successful (KPMG 1999) with six factors ahead (three 'hard keys' and three 'soft keys'). The 'hard keys' correspond to activities that must be performed (synergy evaluation or business fit, integration planning and due diligence); the 'soft keys' correspond to such human resource management aspects as the management team selection, cultural issues and communication with employees, shareholders and vendors. Huang and Kleiner (2004) have also emphasized the role of due diligence activities in estimating a target company. Simpson (2000) adds the importance of integration process, while Pritchett and Gilbreath (1996) underline the assimilation/ integration process, contrary to practices of MandAs in 1980's.

According to the research by Huang and Kleiner (2004), the main obstacle in successfully executing mergers and acquisitions are a cultural barrier, timing and speed of merging, psychological shocks and ineffective communication. Within the study of Coopers and Lybrand (1992) out of 100 interrogated executives of failed mergers 85 mentioned the differences in managing styles as one of the reasons why integrations were not meeting expectations. The study by Deal and Kennedy (1982) examined 80 companies and found out that only 25 companies had clear goals and beliefs (18 of those 25 companies had qualitative beliefs rather than only financially oriented targets, and these companies were identified as undoubtedly the best performers with the strongest organizational culture). These findings suggest that when merging companies the attention should be paid to developing a new organizational culture, creating strong values, being not only financially oriented or looking to exploit the market.

\section{Patterns of demergers and spin-outs}

Panda and Hanumantha (2012) draw attention to another type of structural growth, when companies decentralize rather than concentrate all the activities. The concept of demerger was firstly developed in 1920 s and can be defined as a divestiture of a division or of a part of a company in order to strengthen its' focus on core operations. In some cases demergers refer to spinning out a new company formed with some resources of a parent company (a parent company continues its' activities), however, a company can be also split into two or more new companies, whereas the initial company is liquidated. Weston et al. (1990) examine spin-offs, when a new company is formed from part of another existing company with some shares distributed on a pro rata basis and some assets of parent company transferred to a newly formed entity. The 
United States Securities and Exchange Commission defines spin outs as establishing a new company, in which the equity owners of a parent company receive equity stakes. According to Rumelt (1974), there are five different types of portfolios in terms of activities of a company: single, dominant, related-constrained, related-linked, and unrelated businesses. Companies, where activities are not very interrelated, are more likely to perform spin-offs and do it successfully. Based on the researches by Schipper and Smith (1983) and Hite and Owers (1983), after announcements of spin-offs companies managed to experience positive returns. Although within newly spun-offs some owners get rid of their shares, in many cases companies start to experience the increase in the share price and in the long-term tend to strongly outperform the market averages (Kleiman and Sahu 1992). Cox et al. (1992) compared the pre-spin-off period with periods after companies are spun-off: corporate spin-offs increased the operating efficiency of new companies substantially. According to Woo et al. (1989), small spin-offs are much more successful in generating stronger growth of sales ( $79 \%$ companies), whereas only $23 \%$ of big scale spin-offs showed similar improvements.

The main motives causing structural changes are to enhance benefits received from the newly formed entity and to improve the newly formed company's performance, whereas negative reasons are usually the factors to avoid negative consequences that can be caused by owning a division or department. According to Kirchmaier (2003), the main benefits of demerger include the stronger focus of investors on the newly created company, more clearly defined structure and potential of this company and larger flexibility within the company. Panda and Hanumantha (2012) identify the main drivers of demergers and spin-offs:

1. Desire to raise additional equity from the financial markets.

2. Better concentration on the key activities, allowing to get rid of unnecessary processes and improve financial performance.

3. Reduction of internal competition for funds, allowing newly formed entity to have complete control over its finance allocation.

4. Improvements in governance (newly formed entities tend to have more a clear structure and a more direct involvement from the head office, which allows it to function more efficiently).

5. Reduction in negative synergies, which is a common characteristic of big conglomerates where organizational structure is often complicated and formalized.

Krishnaswari and Subramaniam (1999) add that spin-offs could reduce the information asymmetry in the market about individual divisions of a firm. In conclusion, it can be noted that the key reasons for demergers are the attempts to increase the quality in two areas: clarity and efficiency within the organization, and financing, so that companies could clearly communicate their value to investors and in return receive investments that the market feels they deserve. According to Hellerman and Jones (2000), during the months of transaction and its' planning the important decisions have to be made in such key areas:

- Financial and tax regulations and its impact on organizations;

- Legal matters and issues related to governing;

- Human resource structure, staffing, etc.

- Future interaction and relationship between the newly spun-off company and parent organization;

- Infrastructural matters, which guarantee that the company is able to function and perform its main operations without interruptions and unrelated distractions.

Khan and Mehta (1996) argue that in majority of cases there should be synergies that are worth keeping; also, some companies, even after demerging, have legal obligations to each other. According to Woo et al. (1989), often within the performance of spin-offs the critical strategic benefits, such as synergies, technology transfer or information networks, are forgotten and not taken into account. Gordon (1992) concludes that to successfully execute demergers it is extremely important to take into account the benefits that company can receive from its parent organization, as badly executed spin-off could lead to legal challenges from shareholders, creditors and etc.

\section{Research methodology}

To examine impacts of sustainable structural growth via the main financial indicators first of all there are two conceptual models, summarizing results of the scientific literature analysis and depicting the principle aspects of structural growth sustainability, designed. The models present processes involved in the decision- 
making within structural changes. The figure 1 graphically depicts the key activities in demerger/ spin-off transactions; however, it intentionally lacks the presentation of processes in the integration phase.
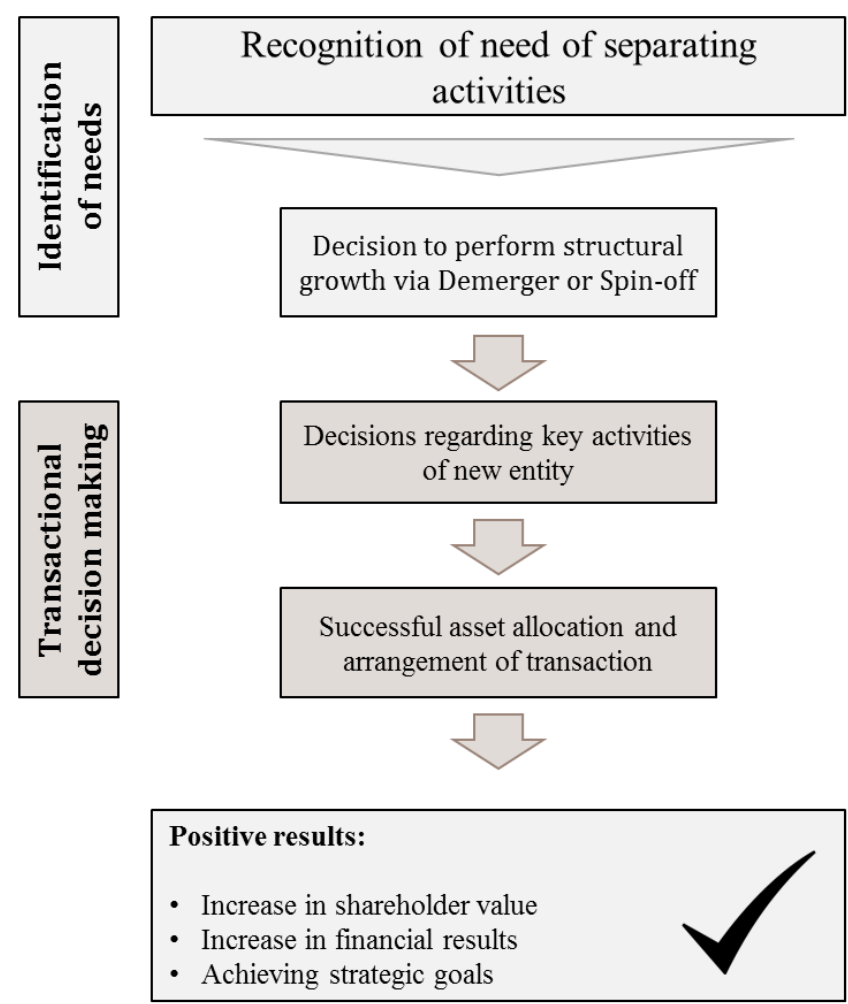
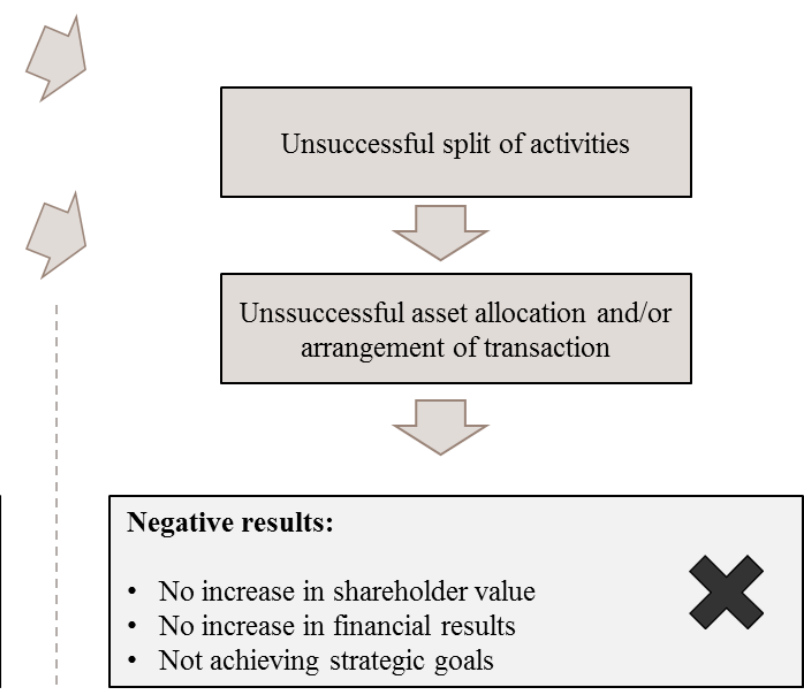

Fig.1. Sequence of decision making processes in demergers and spin-offs

Source: Constructed by authors based on researches by KPMG (1999), Sirower (1997)

The second model below depicts decision making processes involved in executing Mergers and Acquisitions, where the decision making phase is the most important to the success of a transaction, and actions made in this phase determine whether the merger or acquisition is successful (Figure 2).
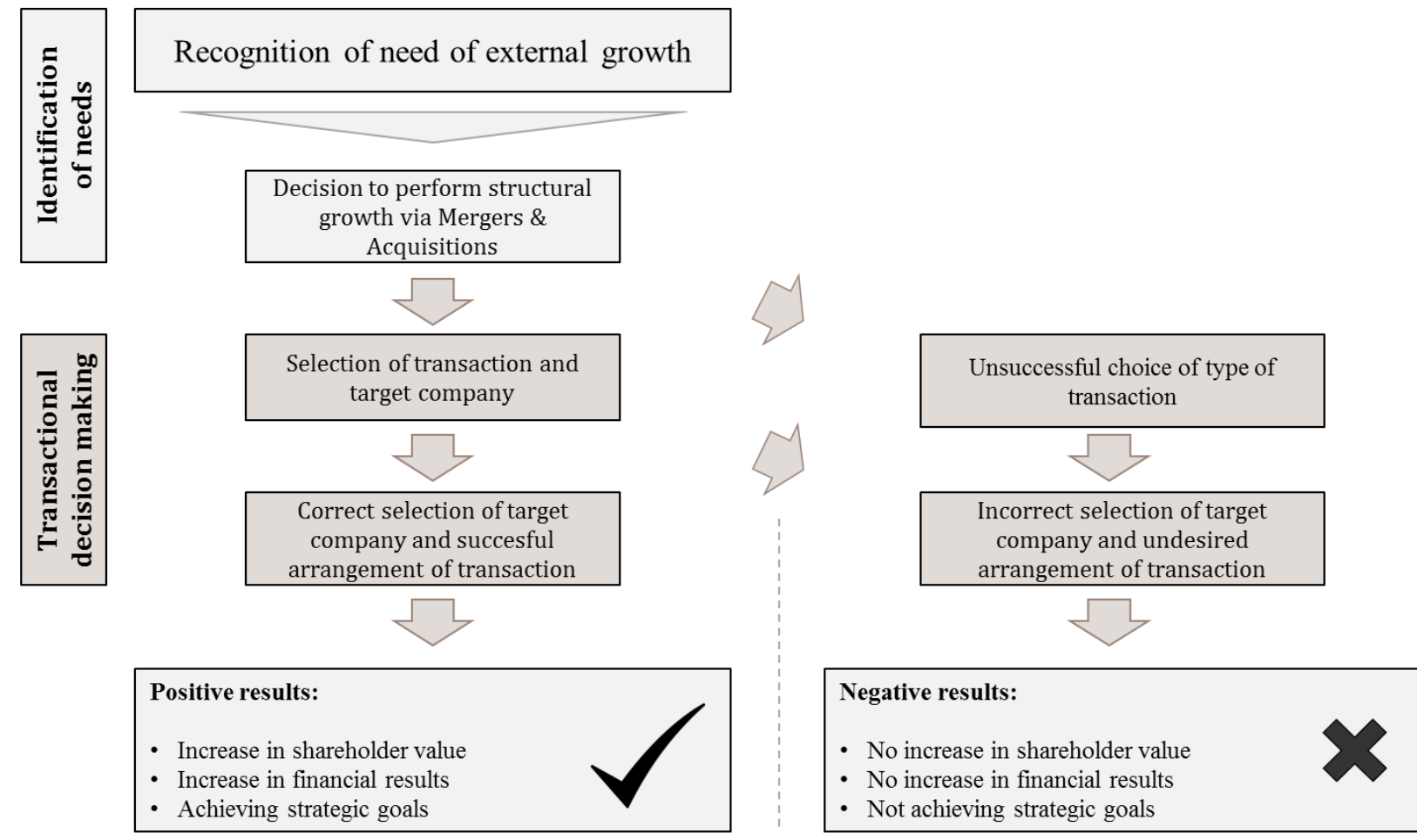

Fig.2. The sequence of decision making processes in mergers and acquisitions Source: Constructed by authors based on researches by KPMG (1999), Sirower (1997) 
The purpose of the present research is to measure the impacts of structural changes on the financial sustainability of companies listed on the stock exchange. It will be executed via a thorough analysis of 4 cases of listed companies that have already experienced similar structural changes. There were both the financial data and results of qualitative interviews with experts scrutinized. All four cases were selected because of directly matching the research problem:

- Altria and its three spin-offs that occurred from 2007 to 2012 in order to split the company, which was once the 11th biggest company in the USA;

- The merger of GDF and Suez, executed in 2010 to form GDF Suez - the 5th biggest company in France;

- The merger of two largest Norwegian IT companies Ergo group an EDB to form Evry ASA in 2010;

- The Norwegian IT company Q-Free, which performed 2 acquisitions of other companies in 2010.

This cluster of companies represent all the main types of structural growth (have experienced structural changes within recent 5-7 years) and are listed on the stock exchange (Oslo, NYSE, Euronext). In total 3 spin-offs, 2 mergers and 2 acquisitions were examined in the research. The analysis of these cases contributes to the verification of conceptual models, while finding out the most important factors of structural changes that have the influence on a sustainable growth of the analysed companies.

The financial sustainability as the illustration of sustainable structural growth was measured by the total revenue, net profit, total market capitalization, shareholder value (capital gains of shareholders), share price and dividends paid to a shareholder. The indicators prior to the transaction and after it were examined. In addition to the analysis of financial statements, representatives of selected companies (working either in the financial department of a company, which is related to Investor Relations, or in the part of a company responsible for mergers and acquisitions) were interrogated. The qualitative interviews were to obtain the information regarding the reasons of structural changes, their execution, impacts, the role of management, main challenges as well as to get the representatives' opinion regarding a sustainable structural growth. The qualitative interviews results were to link the indicators of a company to the key decisions made in the transactional decision-making phase and to see whether there are discrepancies in results that cannot be explained by decision-making in the early stages and how important are factors that are not depicted in the models.

\section{Modelling structural growth and sustainability}

Within the selected cases the structural changes happened for different reasons and, thus, had specific and different targets; the companies' performance also greatly varied from one case to another. The analysis of secondary data revealed that the only analysed company to actually enjoy success despite a global financial crisis was the one which performed structural growth based on decentralization and carried out three spinoffs within 5 years. This allowed companies to be more flexible in the face of crisis and be able to take opportunities faster and more efficiently, as big organizations would normally act slower. Companies that carried out mergers had problems in various areas, as they were able to improve their sales results, but had problems related to their huge organizational structure and were not able to operate efficiently and at higher margins, which caused decreasing net profits and, as a consequence of that, lower share price and shareholder returns, which usually are one of the key goals of a company.

In general, mergers or acquisitions seem to be a very attractive way of sustainable growing for many management teams, as they provide simple and very clear opportunities to grow. Mergers and integration of two or more companies often cause many problems, related to the structure, organizational culture and values, which create many challenges and in some cases completely nullify the benefits received from positive synergies and increased size of a company or acquired competencies.

The findings of the study suggest that spin-offs are a very effective way of downsizing unneeded activities from a company and making it more efficient. However, spin-offs should only be performed after a thorough planning, which ensures that positive synergies within a parent company will not be lost and networking or smaller brand power will not have negative effects on activities. It is very difficult to conclude whether the structural growth has positive or negative effect on the sustainable performance of companies, as there are many factors that come into play and determine whether structural changes will have positive effect on results. The two models designed and presented in the methodology part of the publication were tested. In 
order to depict the success factors and group them according to stages of a transaction, the two models were improved while adding additional elements to these models (Figure 3 ).

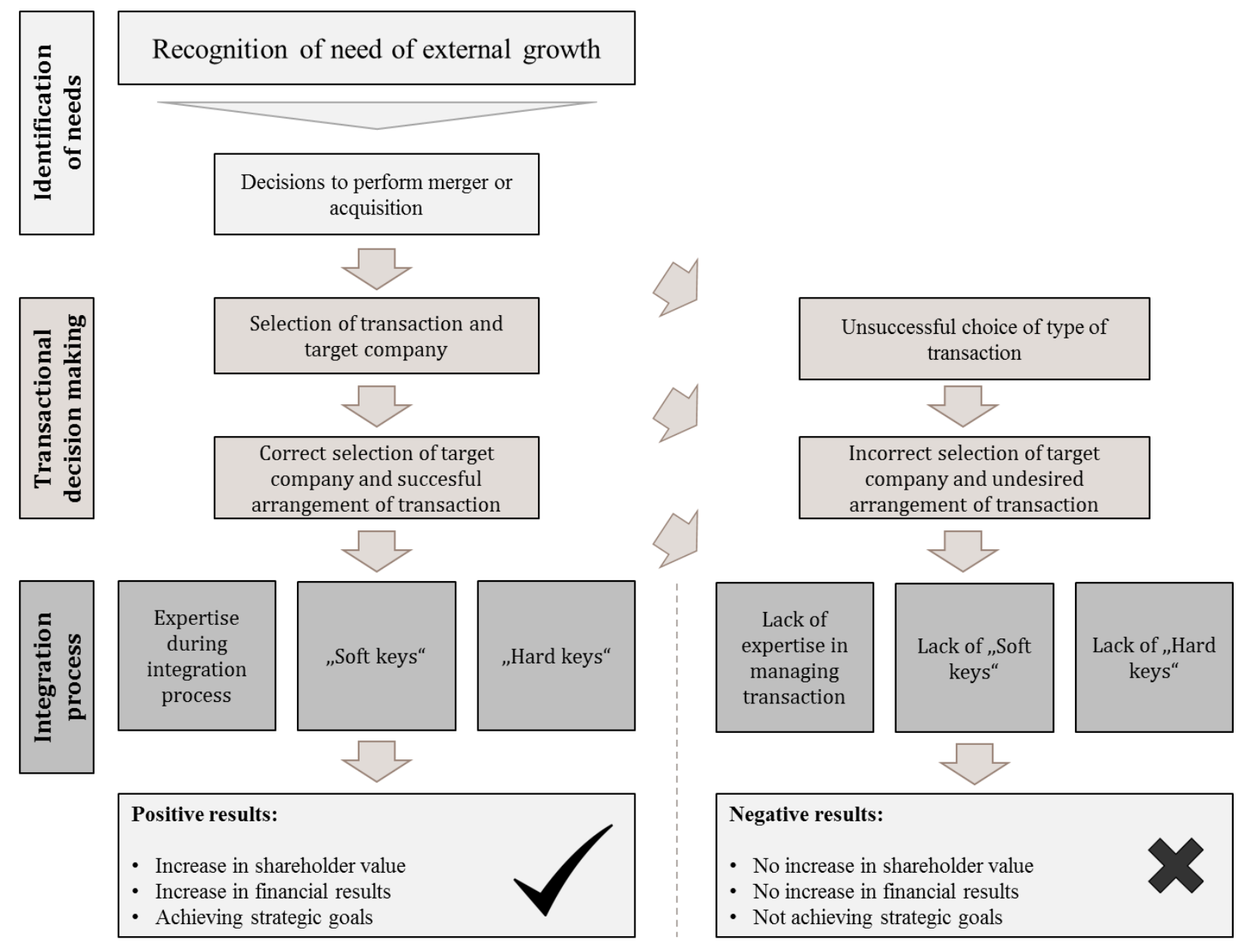

Fig.3. The final model of processes and stages of mergers and acquisitions

Source: Constructed by authors based on researches by KPMG (1999), Sirower (1997), results of research

The integration phase of companies is at least as important as decision-making related to a transaction, and the main key success factors are attributable to this stage of structural growth. Usually structural growth through mergers and acquisitions starts with the acknowledgement of the need to increase the growth and size of a company and evaluation of possible alternatives to achieve that. Once it is determined that a company is willing to acquire another company or merge with it, another important stage in the decisionmaking phase occurs, which is the selection of target companies. The failure at this decision could already determine a complete failure of a transaction. However, if a company chooses the target reasonably, the phase of integration processes begins. In this stage it is still possible that the merger or acquisition will completely fail and the three main groups of processes can be distinguished. The expertise during the integration process is one of the most important factors, as people leading the integration are as crucial to the success of integration as any leader of organization is to the success of that organization. This group is important mainly due to the decision-making which might arise during the integration phase and the need for it to be well-planned.

The 'soft keys' depicted in the graph are the three most important human resource issues: the management team selection, cultural issues and communication. These issues were firstly determined within researches of Huang and Kleiner (2004), and these theories were confirmed by the research performed in this paper.

The 'hard keys' are the three strategic points that are the most important while successfully executing structural changes: synergy evaluation, due diligence and integration planning. If all the mentioned factors are considered and taken into account professionally, it is very likely that the merger or acquisition will be successful, which is usually measured by the increase in the shareholder value, improved financial results and accomplished strategic goals. The second model, which is presented below (Figure 4) depicts processes involved in the execution of demerger or spin-off. 


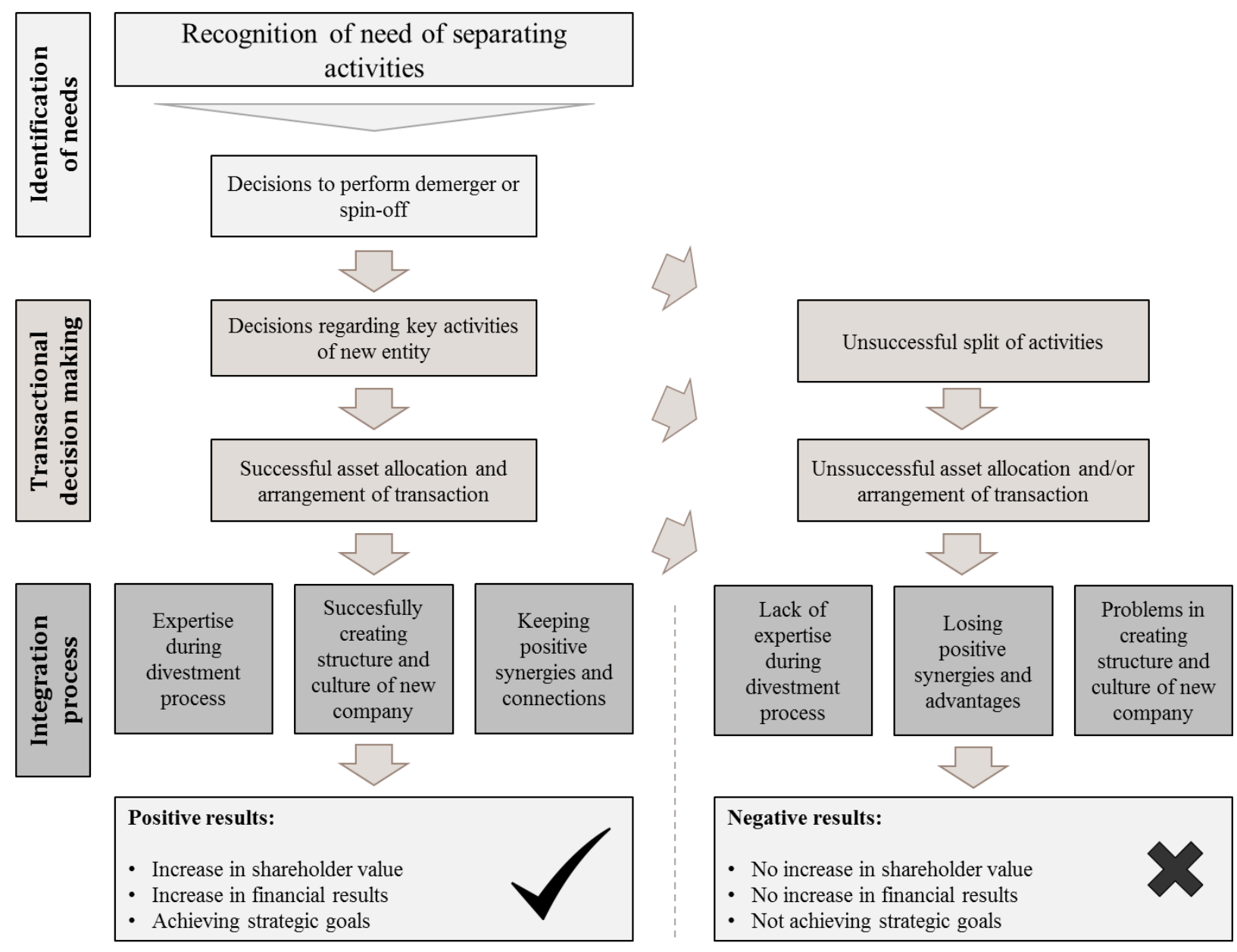

Fig.4. The final model of processes and stages of demergers and spin-offs

Source: Constructed by authors based on researches by KPMG (1999), Sirower (1997), results of research

Similarly to the model of mergers and acquisitions, the processes usually begin by recognizing the need for separating a company into two or more entities and choosing a way of doing this. Once the decision to perform demerger or spin-off is taken, clearly defining activities of new entities and allocating assets to them becomes the primary goal and the first step where the transaction could fail. However, if this stage is executed successfully, the integration processes begin. In this phase, the most important factors, based on the literature review and interviews of representatives of companies, are: professional management of transactions, the recognition of positive synergies and arrangement of keeping such synergies even after the finalization of demerger or spin-off and, finally, the creation of a new organizational structure, culture and set of values.

If all of these mentioned stages are executed in a professional and correct manner, it could be expected that the demerger or spin-off will result in a more efficient and flexible company, which can react to customers' needs more actively and eventually improve its financial results, increase the shareholders' value and achieve the strategic goals and vision.

\section{Conclusions and suggestions}

In general, there are three main types of companies' growth distinguished: organic growth, structural growth and combination of both types. The main target of any transaction, initiated by the management team, should be the increase in the shareholder value and, in general, it should be the main measure of evaluation whether the transaction was successful. There are five main groups of motives for mergers and acquisitions: strategic motives (gaining opportunities for future, acquiring resources, know-how, blocking competitors and etc.), expansion motives (desire to move into new market, expand current market share), personal motives (obtain control over more resources), financial (the opportunity to gain profit from a transaction) or organizational renewal (acquiring new personnel, know-how, technologies). 
The main reasons of demergers and spin-offs that are not caused by the willingness to get rid of unwanted assets include the willingness to focus on the core activities of a company, attempts to eliminate peripheral activities, raising financing of the main and most successful parts of business or attempts to earn profit by buying or selling subsidiaries. In general, it can be grouped into either attempts to have more clear organization, or more efficient financing of companies.

Out of the analysed companies only spin-offs were successful in improving the financial performance and increasing the shareholder value. Companies which executed mergers managed to increase sales results, but not profits or the shareholder value. Acquisitions failed to increase their financial results and did not improve their sale and/ or profits, or the share price and/ or shareholders' returns.

The integration processes in mergers and acquisitions is of significant importance. Two conceptual models were created to graphically depict steps in structural growth. In the case of demergers and spin-offs the two stages in transactions were distinguished: a transactional decision-making and asset allocation, and disintegration process. In the case of mergers and acquisitions the two stages are: a transactional decisionmaking and choosing target companies, and integration processes. The research results and the designed models should serve as a solid background of measuring the economic sustainability of companies mainly due to its multi-factor approach and flexibility.

\section{References}

Baker, H. K.; Miller, T.O.; Ramsperger, B.J. 1981. An Inside look at corporate mergers and acquisitions, MSU Business Topics 29: $49-57$.

Berger, A.N.; Humphrey, D.B. 1992. Megamergers in Banking and the Use of Cost Efficiency as an Antitrust Defense, Antitrust Bulletin 37: 541-600.

Boucher, W.I. 1980. The Process of Conglomerate Merger, Federal Trades Commission, Government Printing Office, Washington.

Coopers and Lybrand. 1992. A review of acquisitions experience of Major UK companies. UK: Coopers and Lybrand, London.

Cornett, M.M.; Tehranian, H. 1992. Changes in corporate performance associated with bank acquisitions, Journal of Financial Economics 31: 211-234.

Cox, R.; Kleiman, R.; Sahu, A. 1992. Strategically planned spin-offs: the empirical evidence, Competitiveness review: an international business journal incorporating Journal of global competitiveness 2(1): 9-12.

Dalton, D.R.; Dalton, C.M. 2006. Corporate growth: Our advice for directors is to buy “organic”, Journal of Business Strategy 27(2): $5-7$.

Danescu, A. 2011. Mergers, acquisitions and external growth, Economics, Management, and Financial Markets 6(3): $179-184$.

Deal, T.E.; Kennedy, A.A. 1982. Corporate cultures. Addison-Wesley, Reading, Mass.

Delaney, F.T.; Wamuziri, S.C. 2004. The Impact of Merger and Acquisitions on Shareholders Wealth in the UK Construction Industry, Engineering, Construction and Architectural management 11: 33-44.

Dodds, J.C.; Quek, J.P. 1985. Effect of Mergers on the share price movement of the acquiring firm - a UK study, Journal of Business Finance and accounting 12(2): 285-296.

Ethier, W.J. 1982. National and International Returns to Scale in the Modern Theory of International Trade, American Economic Review 72(3): 389-405.

Firth, M. 1980. Takeovers, Shareholders' returns and the theory of the Firm, Quarterly Journal of Economics 94(2): 235-260.

Franks, J.; Harris, R. 1989. Shareholder Wealth Effects of Corporate Takeovers - The UK Experience 1955-1985, Journal of Financial Economic 23: 225-249.

Gordon, J. 1992. Spin-offs: A way to increase shareholder value, Journal of Business strategy 13(1): 61-64.

Gould, B. 1998. M and A (Mergers and Acquisitions): not for the average company, The Antidote 3(3): 8-9.

Graebner, M. E.; Eisenhardt, K.M.; Roundy P. T. 2010. Success and failure in technology acquisitions: lessons for buyers and sellers, Academy of Management Perspectives 24(3): 73-92. 
Hall, P.D.; Norburn, D. 1987. The management factor in acquisition performance, Leadership and Organization Development Journal 8(3): 23-30.

Healy, P.; Palepu, K.; Ruback, R. 1992. Does corporate performance improve after mergers?, Journal of Financial Economics 31: $135-175$.

Hellerman, M.; Jones, B. 2000. Spin-Offs: The "Would'ves, Could'ves, and Should'ves" of Spin-Offs, Journal of Business Strategy 21(4): 10-14.

Hite, G.L.; Owers, J.E. 1983. Security Price Reactions Around Corporate Spin-Off Announcements, Journal of Financial Economics 12: 409-436.

Huang, C.T.W.; Kleiner, B.H. 2004. New developments concerning managing mergers and acquisitions, Management Research News 27(4): 54-62.

Irvin, J.; Pedro, L.; Gennaro, P. 2003. Strategy from the inside out: lessons in creating organic growth, Journal of Business Strategy 24(5): 10-14.

Jennings, R.; Mazzeo, M. 1986, Resisting takeovers isn't always bad, Business Horizons (March-April): 56-60.

Jensen, M. Ruback, R. 1983. The Market for Corporate Control - The Scientific Evidence, Journal of Financial Economics 11: 5-50.

Khan, A.Q.; Mehta, D.R. 1996. Voluntary Divestitures and the Choice Between Sell-Offs and Spin-Offs, Financial Review 31: 885912.

Kirchmaier, T. 2003. The performance effects of European demergers. Centre for Economic Performance, London School of Economics and Political Science, London.

Kleiman, R.; Sahu, A. 1992. The market performance of corporate spin-offs, AAII Journal 12(4): 437-467.

Kosedag, A.; Mehran, J.; Qian, J. 2009. Reverse-LBOs, re-LBOs and informational asymmetry hypothesis of LBO transactions, Managerial Finance 35(8): 716-728.

KPMG report on $\mathrm{M}$ and A's. Risk World. 1999. Available on the Internet: <http://www.riskworld.com/pressrel/1999/PR99a214.htm>.

Krishnaswami, S.; Subramaniam, V.R. 1999. Information Asymmetry, Valuation, and the Corporate Spin-off Decision, Journal of Financial Economics 53(1): 73-112.

Kumar, R. 2009. Post-merger corporate performance: an Indian perspective, Management Research news 32(2): 145-157.

Langford, D.; Male, S. 200. Strategic management in construction. Blackwell Science. 2nd edition. London.

Levinson, H. 1970. A Psychologist diagnoses merger failure, Harvard Business Review (March/April): 84-101.

Lithuanian Civil code. 2000. Available on the Internet: 〈http://tm.infolex.lt/?item=taktai_listandaktoid=50801andstrnr=2.97〉

Lockett, A.; Wiklund, J.; Davidsson, P.; Girma S. 2011. Organic and Acquisitive Growth: Re-examining, Testing and Extending Penrose's Growth Theory, Journal of Management Studies 48(1): 48-74.

Maquieira, C.; Megginson, W.; Nail, L. 1998. Wealth Creation Versus Wealth Redistributions in Pure Stock-For-Stock Mergers, Journal of Financial Economics 48: 3-33.

Meer, D. 2005. Enter the “chief growth officer'”: searching for organic growth, Journal of Business Strategy 26(1): 13-17.

Michel, A.; Shaked, I.; Yobaccio, B. 1983. Evidence of Stockholder returns from alternative merger types. Boston university, Boston.

Panda, B.; Hanumantha, R. 2012. Corporate restructuring: Demerging impact, SCMS Journal of Indian Management 9(1): 80-88.

Penrose, E.E.T. 1959. The Theory of the Growth of the Firm. Oxford University Press: New York, New York.

Peters, T.J.; Austen, N. 1985. The Passion for Excellence. Harper and Row, New York.

Poindexter, E.O. 1970. The Profitability of Industrial Merger. Syracuse University, Syracuse.

Pritchett, P.; Gilbreath, R.D. 1996. Mergers: Growth in the fast lane: A field manual for management. Pritchett and Associates, Dallas.

Reddy, K.S.; Nangia V.K.; Agrawal, R. 2013. Corporate mergers and financial performance: a new assessment of Indian cases, Business Review International 4(2): 107 - 129. 
Rumelt, R.P. 1974. Strategy, structure, and economic performance. Cambridge: Harvard University Press, Cambridge.

Samuelson, P.; Nordhaus, W. 2001. Microeconomics. McGraw Hill, $17^{\text {th }}$ edition, New York.

Schipper, K.; Smith, A. 1983. Effects of Recontracting On Shareholder Wealth: The Case of Voluntary Spin-Offs, Journal of Financial Economics 12: 437-467.

Simpson, C. 2000. Integration framework: Supporting successful mergers, Mergers and Acquisitions in Canada 12(10): 3-14.

Sirower, M.L. 1997. The Synergy Trap. The Free Press (Simon and Schuster), New York.

Stacey, N.A.H. 1966. Mergers in Modern Business. Hutchinson, London.

Tosi, H.L.; Werner, S.; Katz, J.P.; Gomez-Mejia, L.R. 2000. How much does performance matter? A meta-analysis of CEO pay studies, Journal of Management 26: 301-339.

Varaiya, N.; Kerin, R.; Weeks, R. 1987. The Relationship between Growth, Profitability and Company Value, Strategic Management Journal 8(5): 487-497.

Wansley, J.W.; Lane, W.R.; Yang, H.C. 1983. Abnormal returns to acquired firms by type of acquisition and method of payment, Financial Management 12(3): 16-22.

Weston, J.; Mitchell, F.L.; Mulherin, J.H. 2004. Takeovers, Restructuring, and Corporate Governance. Pearson Prentice Hall, New Jersey.

Weston, F.J.; Chung, S.K.; Hoag, S. 1990. Mergers, restructuring and corporate control. Prentice Hall, New Jersey.

Woo, C.; Willard, G.; Beckstead, S. 1989. Spin-offs: What are the gains?, Journal of Business Strategy 10(2): $433-447$.

Dr. Mindaugas Laužikas is associate professor at International Business School of Vilnius University, Lithuania. His researches are related to national systems of innovation, entrepreneurship, knowledge diffusion as well as innovation and human resource strategies. Mindaugas Laužikas is the leader of Lithuanian team of Global Entrepreneurship Monitor (GEM), involved in executive education and consultancy.

Antanas Krasauskas is researcher and analyst focusing on such fields as sustainable finances, economic performance of companies, innovation, knowledge diffusion and entrepreneurship. 